\title{
Canadian Urological Association Best Practice Report: Diagnosis and management of sporadic angiomyolipomas
}

Yanbo Guo, MD ${ }^{1}$; Anil Kapoor, MD, FRCSC ${ }^{1}$; Paul Cheon, $\mathrm{MD}^{1}$; Alan I. So, MD, FRCSC ${ }^{2}$; JeanBaptiste Lattouf, MD, FRCSC ${ }^{3}$; Munir Jamal, MD, FRCSC ${ }^{4}$

${ }^{1}$ Division of Urology, Department of Surgery, McMaster University, Hamilton, ON, Canada; ${ }^{2}$ Department of Urologic Sciences, University of British Columbia, Vancouver, BC, Canada; ${ }^{3}$ Departments of Surgery and Urology, Centre Hospitalier de l'Université de Montréal, Montreal, QC, Canada; ${ }^{4}$ Division of Urology, Department of Surgery, Trillium Health Partners, Mississauga, ON, Canada

Cite as: Guo Y, Kapoor A, Cheon P, et al. Canadian Urological Association Best Practice Report: Diagnosis and management of sporadic angiomyolipomas. Can Urol Assoc J 2020 September 8; Epub ahead of print. http://dx.doi.org/10.5489/cuaj.6942

Published online September 8, 2020

$* * *$

\section{Introduction}

Angiomyolipomas (AML) are benign neoplasms composed of varying amounts of blood vessels, smooth muscle and adipose tissue. While being the most frequently occurring benign solid renal tumour, their incidence in the general population is still uncommon, occurring with a frequency of 13 to 30 per $100000 .{ }^{1}$ With the increased use of intra-abdominal sonography and cross-sectional imaging, more have been incidentally identified. ${ }^{2}$

The majority of these tumours are asymptomatic, but some present with symptoms including flank pain, hematuria, and rarely, life-threatening hemorrhage. The frequency of these presentations has been controversial and a point of contention in their management. In an influential case series and literature review of 253 patients, Oesterling et al. reported that $64 \%$ were symptomatic, and $40 \%$ presented with hemorrhage. These numbers became more dramatic in tumours larger than $4 \mathrm{cms}$, with $82 \%$ being symptomatic and $51 \%$ presenting with hemorrhage. ${ }^{3}$ This landmark review greatly influenced the $4 \mathrm{~cm}$ cut off has been ingrained into urologic literature and the historically high rate of intervention in lesions larger than $4 \mathrm{~cm} .{ }^{4}$

In contrast, contemporary series have reported much more modest rates of $10 \%$ being symptomatic and only $2 \%$ risk of hemorrhage. ${ }^{5}$ The lack of prospective randomized studies in the management of AMLs and the significant heterogeneity in the available retrospective evidence presents a conundrum in clinical management.

While the majority of AMLs are sporadic, up to $20 \%$ are associated with hereditary conditions such as tuberous sclerosis complex (TSC) and lymphangioleiomyomatosis (LAM). ${ }^{4}$ Management of these lesions tends to differ from sporadic AMLs as they tend to present with multiple tumours and seem 
to respond well to mTOR inhibitors. In contrast, there is currently no indication nor data supporting the treatment of sporadic AML with mTOR inhibitor therapy. In patients with synchronous bilateral AMLs or clinical symptoms consistent with hereditary conditions, referral for further assessment and genetic testing should be discussed. The vast majority of AMLs in children are associated with syndromic conditions. Sporadic AMLs are extremely rare in children with minimal published data available. ${ }^{6}$ Given the paucity of data and experience for children diagnosed with AMLs on imaging, referral to a tertiary pediatric center should be strongly considered. This Best Practice Report (BPR) will focus on the sporadic form of AML in adults only.

Diagnosis, follow up protocol, as well as indications for and type of management for the sporadic AML vary widely. This BPR seeks to codify existing data to provide practicing urologists with the best evidence-based recommendations to inform decision making in the management of sporadic AML. The following clinical questions will be discussed:

1. What imaging tests are necessary to confirm the diagnosis of AMLs?

2. What is the natural history of AMLs?

3. What is the optimum follow up protocol for AMLs under observation?

4. What are the indications for intervention?

5. What interventions are available and preferred?

6. What is the management of acutely bleeding AMLs?

\section{Methods}

The search strategy registered on PROSPERO and was done electronically on OVID using MEDLINE and EMBASE. Given the limited amount of literature on the subject, articles regarding diagnosis and treatment were all grouped together in one search. Search terms included "angiomyolipoma OR AML" and excluded "liver OR hepatic," "tuberous sclerosis OR TSC," "lymphangioleiomyomatosis OR LAM," "case report." The search was limited to peer-reviewed articles published in English since 1995 with adult (age $>18$ ) human subjects. 468 studies were screened, and 159 studies underwent full-text review. Disagreements between the two reviewers (Y.G. \& P.C.) were resolved by consensus. In general, there were no prospective comparative trials available. Reported patient, lesions, and outcomes varied significantly. There were no prospective comparative trials identified (Fig. 1).

\section{Diagnosis}

\section{Recommendation \#1: All cases of suspected renal AML should be confirmed with either unenhanced CT, contrast-enhanced CT, or MRI. Percutaneous biopsy should be considered if neither CT nor MRI are diagnostic.}

The radiological diagnosis of AMLs is dependent on the detection of intertumoral fat. On ultrasound, the fat content in these lesions result in a characteristic appearance of a hyperreflective lesion with acoustic shadowing. ${ }^{7}$ However, up to $30 \%$ of small $(<3 \mathrm{~cm})$ renal cell carcinomas $(\mathrm{RCC})$ can mimic this appearance, reducing the specificity of US. ${ }^{8}$ There is also a small proportion of AMLs (5\%) that have 
significantly lower fat content, traditionally referred to as minimal fat AMLs, and may not have this characteristic appearance on US. ${ }^{9}$ To improve the accuracy of US, adjunct methods such as doppler or contrast-enhanced US have been investigated. However, even with the use of both adjuncts, Ascenti et al. reported a diagnostic accuracy of $78 \%$ when compared to pathological diagnosis. ${ }^{10}$ Unenhanced computed tomography (UECT) is sensitive to detecting macroscopic fat in renal lesions. Although attenuation values of $<10 \mathrm{HU}$ in ROI are most often used to confirm fat, some have advocated for a lower cut off of -15 or $-30 \mathrm{HU}$ to increase specificity. ${ }^{11}$ Thinner slices have also been demonstrated to detect intralesional fat in smaller AMLs, with $3 \mathrm{~mm}$ to $5 \mathrm{~mm}$ slices identifying the vast majority of lesions. ${ }^{12,13}$

While the majority of AMLs can be diagnosed with UECT, the majority of the patients worked up for an undifferentiated renal mass will undergo a multiphasic contrast-enhanced CT (CECT). AMLs generally demonstrate homogenous enhancement, delayed washout and high intrinsic attenuation. The addition of contrast does not add significantly to the sensitivity of CT for the diagnosis of AML. Woo et al. published a meta-analysis of 15 studies with 2258 patients demonstrating multiple feature analysis of CECT finding similar sensitivity to UECT ( $78 \%$ vs $81 \%) .{ }^{14}$

Similar to UECT, MRI is excellent at identifying intralesional fat and may be more sensitive. Classically, fat appears hyperintense on T1 sequences and hypointense on T2 images. However, hemorrhagic cysts can have a similar appearance, and, in these cases, chemical shift fat suppression sequences may be useful. ${ }^{18}$ This has also been shown to help identify minimal fat AMLs. Song et al. reviewed 98 pathologically confirmed minimal fat AMLs and found that $23 \%$ of them were identifiable on MRI but not CT. ${ }^{19}$ However, there remained another $23 \%$ of histologically confirmed AML that were not discernable on CT or MRI. Song also proposed radiologically based categories for AMLs. Those with fat visible on CT were termed "fat-rich." The remainder, which would have been traditionally called minimal fat AMLs, further subdivided into "fat-poor" and "fat-invisible." Fat-poor AMLs were only identifiable with additional MRI imagining, while fat invisible AMLs remain inconclusive. ${ }^{19}$

Although the diagnosis of AML depends on the identification of intra-tumoural fat, some rare fat-containing tumours may be malignant. Wilms tumours, extremely rare in adults, should be considered in pediatric populations. Liposarcomas are most often perirenal rather than developing from the kidney, and usually demonstrate renal displacement. ${ }^{15}$ Rarely RCC may contain fat, especially large ones that entrap perirenal or sinus fat, or have calcifications representing osseous metaplasia. ${ }^{16}$

Epithelioid AMLs (EAMLs) are a rare variant of AMLs that are composed of epithelioid cells, with an absence of adipocytes and abnormal vessels. ${ }^{20}$ While classified with classic AMLs, they can demonstrate malignant behaviour. The majority of evidence we have regarding EAMLs is from case reports, and between $18-49 \%$ of these have been estimated to be malignant. ${ }^{21,22}$ Given the controversy over their malignant potential, some have further subdivided these lesions into pure EAMLs and AMLs with epithelioid components, with pure EAMLs more likely to be considered high risk for metastatic spread. However, while EAMLs belong to the same pathological family as AMLs, they rarely resemble classic AMLs radiologically. The lack of adipose tissue in these lesions, particularly pure EAMLs, result 
in them being usually diagnosed as either RCCs or indeterminate/fat invisible AMLs. ${ }^{17,22}$ However, it must be noted that there remain rare case reports where these lesions were initially diagnosed as classic AMLs and only differentiated on pathology. ${ }^{23}$ Unfortunately, given the lack of evidence, it is difficult to determine the incidence of such rare misclassifications. EAMLs must remain a consideration in the evaluation of fat invisible lesions.

As there is no reliable way of imaging to differentiate fat invisible AMLs from atypical appearing RCCs or EAMLs, they may be managed as indeterminate solid renal masses and may require biopsy for diagnosis. A recent metanalysis on renal mass biopsies of 57 studies and 5228 patients from Marconi et al. found an overall accuracy of $92 \%$ and only three significant (Clavian grade 2 or greater) complications. ${ }^{24}$ They also found that core biopsies had a high sensitivity and specificity compared to fine needle aspiration, $99.1 \%$ and $99.7 \%$, compared to $93.2 \%$ and $89.8 \%$, respectively. There is also evidence that FNA may be particularly challenging in diagnosing AMLs. Zhou et al. reviewed the FNA biopsies of 33 surgically diagnosed AMLs and found that only $49 \%$ of them were diagnosed correctly, with the remainder being non-diagnostic or described as RCCs. ${ }^{25}$

For lesions that are diagnosed as EAMLs or remain undifferentiated after biopsy, surgical resection is recommended, regardless of lesions size. After resection of pathologically confirmed EAMLs, there is no evidence for adjuvant therapy and observation is recommended. There is no data or evidence to suggest a follow-up schedule. However, applying the RCC follow-up guidelines may be reasonable. ${ }^{26}$ In cases of metastatic EAMLs, again there is little evidence to guide local or systemic therapy but there are case reports of response to doxorubicin and everolimus. ${ }^{27,28}$

\section{Natural history}

The natural history of AMLs has been controversial and has played a significant role in treatment decision making. Our review of contemporary reviews of AMLs on active surveillance identified nine articles with 1137 patients. It is important to note that these are all retrospective reviews of patients selected to be on active surveillance and likely represent a favourable cohort. We found that over the average follow up period of 37 months, $92 \%$ of AMLS observed were asymptomatic. The vast majority of AMLs remained stable in size, and only $9 \%$ of these lesions grew with an average growth rate of $0.4 \mathrm{~mm} /$ year. The hemorrhage rate was also quite low, at $3 \%$. No lesions that were diagnosed to be malignant during follow up.

Due to the influence of Oesterling's original paper, of the four articles that did differentiate outcomes by the size of the lesion, three used the $4 \mathrm{~cm}$ cut-off. When stratified by size, we found that lesions $>4 \mathrm{~cm}$ appeared to be at a higher risk to be symptomatic ( $34 \%$ vs $6 \%$ ), grow $(25 \%$ vs $2 \%)$ and hemorrhage (16\% vs $1 \%$ ). Examining individual articles that compared AMLs by size reveal significant heterogeneity of results. Maclean et al found that lesions $>4 \mathrm{~cm}$ grew significantly faster than those $<2 \mathrm{~cm}$ (OR of 13.3 and $\mathrm{p}=0.02$ ) while Bhatt et al found no difference $(0.17 \mathrm{~mm} /$ year vs $0.2 \mathrm{~mm} /$ year, $\mathrm{p}=0.86) .{ }^{5,29}$ Ouzaid et al. found that tumour size was significant as an independent predictor of discontinuation of AS for any reason (HR of 11.2, $\mathrm{p}=0.001$ ) while Yamakato found that size was not a significant independent predictor of hemorrhage $(\mathrm{p}=0.07) .{ }^{30,31}$ Based on our systematic review presented 
in Table 1 , AMLs $>4 \mathrm{~cm}$ did appear to be at a higher risk of hemorrhage compared to those $<4 \mathrm{~cm}(1 \% \mathrm{vs}$ $16 \%$ ), or undergoing intervention ( $1 \%$ vs $34 \%$ ). The absolute risk, however, is much lower than originally described by Oesterling et al. We were also unable to find any high-level evidence demonstrating any statistically significant correlation between size and hemorrhage.

\section{Followup}

Recommendation \#2: Once the diagnosis of AML is made, imaging and clinical evaluation should be carried out periodically. Traditionally, surveillance has been done on a biannual or annual basis, but consideration should be given to decreasing frequency once stability has been established. A decision for the cessation of monitoring should involve a discussion between provider and patient, weighing risks and benefits.

Oesterling's original paper recommended annual imaging for AMLs smaller than 4cm and biannually for AMLs larger than $4 \mathrm{~cm}$. Unfortunately, there have been no prospective studies to help guide our follow up protocols since then. Our systematic review found that these lesions generally grow quite slowly, with average growth rates ranging from 0.1 to $1 \mathrm{~mm} /$ year, meaning it could take up ten years to grow $1 \mathrm{~cm}$. However, there were outliers described in the case series, growing up to $1.5 \mathrm{~cm}$ per year. ${ }^{36}$ Based on this, annual monitoring (or less frequently) would seem reasonable for the majority of lesions, and it may be reasonable to initially image more regularly and reduce frequency once stability is demonstrated. The majority of follow up protocols we identified in our literature review used this strategy, with initially biannual imaging and then annual imaging after one year.

There is also limited evidence for identifying optimum imaging modality. While US alone is not sufficient for the diagnosis of AMLs, there is no evidence that CT or MRI improves follow up care. An ideal follow up protocol would minimize the risks of ionizing radiation and the costs of axial imaging. Another consideration is what duration of time routine imaging should continue for. The most prolonged follow-up protocol we found in our review was for approximately five years. However, given the lack of evidence, cessation of follow-up should be a shared decision between patient and provider, taking into account the patient's general health status and competing risks of mortality, as well as their goals and concerns.

For indeterminate lesions, malignant lesions such as RCC or epithelioid AMLs cannot be ruled out. If proceeding with active surveillance, these require more careful monitoring for progression.

\section{Indications for intervention}

Recommendation \#3: The vast majority of AMLs are asymptomatic, have a low risk of hemorrhage and can be monitored. There does appear to be an increased risk of symptoms and hemorrhage in lesions larger than $4 \mathrm{~cm}$, but this is not based on high-level evidence. Symptomatic AML should be treated to ameliorate symptoms. Treatment for asymptomatic AML $>4 \mathrm{~cm}$ should be discussed, with the understanding that the absolute risks of hemorrhage are lower than 


\section{previously thought. Other factors that may influence the desire to treat include access to health care, women of childbearing age, and patient preferences.}

Up to $92 \%$ of AMLs in contemporary series are asymptomatic; however, when symptoms are present, treatment should be considered to improve symptoms. Symptoms such as flank pain, palpable mass or gross hematuria are more likely in larger lesions. ${ }^{4}$ Based on natural history and the minimal risk of hemorrhage, small AML $(<4 \mathrm{~cm})$ rarely require intervention.

For AMLs larger than $4 \mathrm{~cm}$, treatment should be discussed. While they do appear to be at a higher risk, the absolute risk of spontaneous hemorrhage seems lower than previously estimated, and there is limited evidence for an absolute size threshold. In addition to size, several other factors may play a role in assessing the risk of hemorrhage of untreated AML. The presence of aneurysms and aneurysmal size has been linked to the risk of hemorrhage in several studies. ${ }^{31}$ However, intratumoural aneurysms can only be reliably assessed through angiography and may not be clinically feasible for the majority of cases. ${ }^{38,39}$

Ongoing surveillance is a necessary pillar of AML management. For patients who have poor access to imaging or emergency care treatment, or who do not desire long term monitoring, consideration (weighing risks/benefits) may be given to intervention.

Finally, hemorrhage of AML during pregnancy is an uncommon yet greatly feared complication. There may be a physiologic basis to this increased risk with estrogen receptor expression strongly associated with AMLs. ${ }^{40}$ The only clinical evidence we have to rely upon are case reports. Cetin et al. reviewed 26 case reports of AML during pregnancy in literature from 1994 to 2015 and found 81\% presented with rupture (mean size $11 \mathrm{~cm}$ ). Current evidence for rupture in this population is extremely weak and is based on case reports and a physiologic hypothesis. ${ }^{41,42}$ However, given the high trade-offs, the treatment of AMLs should be considered and discussed with reproductive-age women. These recommendations are consistent with the most recent EAU RCC guidelines.

\section{Interventions}

\section{Acutely bleeding AMLs}

\section{Recommendation \#5: Transcatheter embolization should be the first-line treatment for acutely bleeding AML.}

There have not been any prospective trials comparing interventions in acutely hemorrhaging AMLs. Traditionally, selective TAE has been the first-line treatment. ${ }^{4}$ Compared to surgery, TAE is minimally invasive and preserves renal function compared to surgery, especially given the concern for the requirement of radical nephrectomy in this setting.

While this is minimal data in the acute setting, in general, embolization does appear to be associated with fewer complications but may have an increased risk of repeat intervention. ${ }^{43} \mathrm{~A}$ surgical 
approach may be considered in patients that are hemodynamically unstable despite adequate supportive care. $^{44}$

Acutely hemorrhaging AML in a pregnant woman is an extremely uncommon yet complex emergency that should be treated by a multidisciplinary team. In a hemodynamically stable patient, with no sign of fetal distress, conservative management in a monitored setting can be attempted.

Embolization and surgery are both options. In general, embolization offers a less invasive option, but factors such as fetal distress and maturity may make surgery the preferable option if an emergent Csection is mandated. ${ }^{42}$

\section{Conclusions}

Sporadic AMLs are seen and managed by most practicing urologists. The vast majority of these can be diagnosed radiologically with CT or MRI. While the risk of spontaneous retroperitoneal hemorrhage is present, this is much lower than originally described. Surveillance is a reasonable option in many of these cases. Despite the low level of evidence available, the previously prescribed strict $4 \mathrm{~cm}$ size cut off for active intervention management is not supported by evidence in contemporary series. There is no evidence for the superiority of surgery or embolization for treatment. A proposed management algorithm is presented in Fig. 2. 


\section{References}

1. Eble JN. Angiomyolipoma of kidney. Semin Diagn Pathol. 1998;15(1):21-40

2. Fujii Y, Ajima J, Oka K, Tosaka A, Takehara Y. Benign renal tumors detected among healthy adults by abdominal ultrasonography. Eur Urol. 1995;27(2):124-127. doi:10.1159/000475142

3. Oesterling JE, Fishman EK, Goldman SM, Marshall FF. The management of renal angiomyolipoma. J Urol. 1986;135(6):1121-1124. doi:10.1016/s0022-5347(17)46013-7

4. Nelson CP, Sanda MG. Contemporary diagnosis and management of renal angiomyolipoma. J Urol. 2002;168(4 Pt 1):1315-1325. doi:10.1097/01.ju.0000028200.86216.b2

5. Bhatt JR, Richard PO, Kim NS, et al. Natural History of Renal Angiomyolipoma (AML): Most Patients with Large AMLs $>4 \mathrm{~cm}$ Can Be Offered Active Surveillance as an Initial Management Strategy. Eur Urol. 2016;70(1):85-90. doi:10.1016/j.eururo.2016.01.048

6. Tchaprassian Z, Mognato G, Paradias G, D'Amore ES, Tregnaghi A, Cecchetto G. Renal angiomyolipoma in children: diagnositc difficulty in 3 patients. J Urol. 1998;159(5):1654-1656. doi:10.1097/00005392-199805000-00083

7. Hartman DS, Goldman SM, Friedman AC, Davis CJ Jr, Madewell JE, Sherman JL. Angiomyolipoma: ultrasonic-pathologic correlation. Radiology. 1981;139(2):451-458. doi:10.1148/radiology.139.2.7220890

8. Forman HP, Middleton WD, Melson GL, McClennan BL. Hyperechoic renal cell carcinomas: increase in detection at US. Radiology. 1993;188(2):431-434. doi:10.1148/radiology.188.2.8327692

9. Kim JK, Park SY, Shon JH, Cho KS. Angiomyolipoma with minimal fat: differentiation from renal cell carcinoma at biphasic helical CT. Radiology. 2004;230(3):677-684. doi:10.1148/radiol.2303030003

10. Ascenti G, Zimbaro G, Mazziotti S, Gaeta M, Settineri N, Scribano E. Usefulness of power Doppler and contrast-enhanced sonography in the differentiation of hyperechoic renal masses. Abdom Imaging. 2001;26(6):654-660. doi:10.1007/s00261-001-0025-8

11. Lemaitre L, Claudon M, Dubrulle F, Mazeman E. Imaging of angiomyolipomas. Semin Ultrasound CT MR. 1997;18(2):100-114. doi:10.1016/s0887-2171(97)90054-8

12. Kurosaki Y, Tanaka Y, Kuramoto K, Itai Y. Improved CT fat detection in small kidney angiomyolipomas using thin sections and single voxel measurements. J Comput Assist Tomogr. 1993;17(5):745-748. doi:10.1097/00004728-199309000-00015

13. Bosniak MA, Megibow AJ, Hulnick DH, Horii S, Raghavendra BN. CT diagnosis of renal angiomyolipoma: the importance of detecting small amounts of fat. AJR Am J Roentgenol. 1988;151(3):497-501. doi:10.2214/ajr.151.3.497

14. Woo S, Suh CH, Kim SY, Cho JY, Kim SH. Diagnostic Performance of Prostate Imaging Reporting and Data System Version 2 for Detection of Prostate Cancer: A Systematic Review and Diagnostic Meta-analysis. Eur Urol. 2017;72(2):177-188. doi:10.1016/j.eururo.2017.01.042

15. Israel GM, Bosniak MA, Slywotzky CM, Rosen RJ. CT differentiation of large exophytic renal angiomyolipomas and perirenal liposarcomas. AJR Am J Roentgenol. 2002;179(3):769-773. doi:10.2214/ajr.179.3.1790769

16. Halpenny D, Snow A, McNeill G, Torreggiani WC. The radiological diagnosis and treatment of renal angiomyolipoma-current status. Clin Radiol. 2010;65(2):99-108. doi:10.1016/j.crad.2009.09.014 
17. Huang KH, Huang CY, Chung SD, Pu YS, Shun CT, Chen J. Malignant epithelioid angiomyolipoma of the kidney. J Formos Med Assoc. 2007;106(2 Suppl):S51-S54. doi:10.1016/s0929-6646(09)60353-3

18. Kim JK, Kim SH, Jang YJ, et al. Renal angiomyolipoma with minimal fat: differentiation from other neoplasms at double-echo chemical shift FLASH MR imaging. Radiology. 2006;239(1):174-180. doi:10.1148/radiol.2391050102

19. Song S, Park BK, Park JJ. New radiologic classification of renal angiomyolipomas. Eur J Radiol. 2016;85(10):1835-1842. doi:10.1016/j.ejrad.2016.08.012

20. Lin CY, Yang CK, Ou YC, et al. Long-term outcome of robotic partial nephrectomy for renal angiomyolipoma. Asian J Surg. 2018;41(2):187-191. doi:10.1016/j.asjsur.2016.11.003

21. Brimo F, Robinson B, Guo C, Zhou M, Latour M, Epstein JI. Renal epithelioid angiomyolipoma with atypia: a series of 40 cases with emphasis on clinicopathologic prognostic indicators of malignancy. Am J Surg Pathol. 2010;34(5):715-722. doi:10.1097/PAS.0b013e3181d90370

22. Lee W, Choi SY, Lee C, et al. Does epithelioid angiomyolipoma have poorer prognosis, compared with classic angiomyolipoma?. Investig Clin Urol. 2018;59(6):357-362. doi:10.4111/icu.2018.59.6.357

23. Varma S, Gupta S, Talwar J, Forte F, Dhar M. Renal epithelioid angiomyolipoma: a malignant disease. J Nephrol. 2011;24(1):18-22. doi:10.5301/jn.2010.5451

24. Marconi L, Dabestani S, Lam TB, et al. Systematic Review and Meta-analysis of Diagnostic Accuracy of Percutaneous Renal Tumour Biopsy. Eur Urol. 2016;69(4):660-673. doi:10.1016/j.eururo.2015.07.072

25. Zhou H, Guo M, Gong Y. Challenge of FNA diagnosis of angiomyolipoma: A study of 33 cases. Cancer Cytopathol. 2017;125(4):257-266. doi:10.1002/cncy.21824

26. Kassouf W, Monteiro LL, Drachenberg DE, et al. Canadian Urological Association guideline for followup of patients after treatment of non-metastatic renal cell carcinoma. Can Urol Assoc J. 2018;12(8):231-238. doi:10.5489/cuaj.5462

27. Cibas ES, Goss GA, Kulke MH, Demetri GD, Fletcher CD. Malignant epithelioid angiomyolipoma ('sarcoma ex angiomyolipoma') of the kidney: a case report and review of the literature. Am J Surg Pathol. 2001;25(1):121-126. doi:10.1097/00000478-200101000-00014

28. Kohno J, Matsui Y, Yamasaki T, et al. Role of mammalian target of rapamycin inhibitor in the treatment of metastatic epithelioid angiomyolipoma: a case report. Int J Urol. 2013;20(9):938941. doi:10.1111/iju.12095

29. Maclean DF, Sultana R, Radwan R, McKnight L, Khastgir J. Is the follow-up of small renal angiomyolipomas a necessary precaution?. Clin Radiol. 2014;69(8):822-826. doi:10.1016/j.crad.2014.03.016

30. Ouzaid I, Autorino R, Fatica R, et al. Active surveillance for renal angiomyolipoma: outcomes and factors predictive of delayed intervention. BJU Int. 2014;114(3):412-417. doi:10.1111/bju. 12604

31. Yamakado K, Tanaka N, Nakagawa T, Kobayashi S, Yanagawa M, Takeda K. Renal angiomyolipoma: relationships between tumor size, aneurysm formation, and rupture. Radiology. 2002;225(1):78-82. doi:10.1148/radiol.2251011477

32. Swärd J, Henrikson O, Lyrdal D, Peeker R, Lundstam S. Renal angiomyolipoma-patient characteristics and treatment with focus on active surveillance. Scand J Urol. 2020;54(2):141146. doi: $10.1080 / 21681805.2020 .1716066$ 
33. Chan KE, Chedgy E, Bent CL, Turner KJ. Surveillance imaging for sporadic renal angiomyolipoma less than $40 \mathrm{~mm}$ : lessons learnt and recommendations from the experience of a large district general hospital. Ann R Coll Surg Engl. 2018;100(6):480-484. doi:10.1308/rcsann.2018.0040

34. Ruud Bosch JLH, Vekeman F, Duh MS, et al. Factors associated with the number and size of renal angiomyolipomas in sporadic angiomyolipoma (sAML): a study of adult patients with sAML managed in a Dutch tertiary referral center. Int Urol Nephrol. 2018;50(3):459-467. doi:10.1007/s11255-017-1766-9

35. Fittschen A, Wendlik I, Oeztuerk S, et al. Prevalence of sporadic renal angiomyolipoma: a retrospective analysis of 61,389 in- and out-patients. Abdom Imaging. 2014;39(5):1009-1013. doi:10.1007/s00261-014-0129-6

36. Mues AC, Palacios JM, Haramis G, et al. Contemporary experience in the management of angiomyolipoma. J Endourol. 2010;24(11):1883-1886. doi:10.1089/end.2010.0223

37. De Luca S, Terrone C, Rossetti SR. Management of renal angiomyolipoma: a report of 53 cases. BJU Int. 1999;83(3):215-218. doi:10.1046/j.1464-410x.1999.00932.x

38. Champagnac J, Melodelima C, Martinelli T, et al. Microaneurysms in renal angiomyolipomas: Can clinical and computed tomography features predict their presence and size?. Diagn Interv Imaging. 2016;97(3):321-326. doi:10.1016/j.diii.2015.12.004

39. Rimon U, Duvdevani M, Garniek A, et al. Large renal angiomyolipomas: digital subtraction angiographic grading and presentation with bleeding. Clin Radiol. 2006;61(6):520-526. doi:10.1016/j.crad.2006.02.003

40. Boorjian SA, Sheinin Y, Crispen PL, Lohse CM, Kwon ED, Leibovich BC. Hormone receptor expression in renal angiomyolipoma: clinicopathologic correlation. Urology. 2008;72(4):927932. doi:10.1016/j.urology.2008.01.067

41. Çetin C, Büyükkurt S, Demir C, Evrüke C. Renal angiomyolipoma during pregnancy: Case report and literature review. Turk J Obstet Gynecol. 2015;12(2):118-121. doi:10.4274/tjod.32848

42. Preece P, Mees B, Norris B, Christie M, Wagner T, Dundee P. Surgical management of haemorrhaging renal angiomyolipoma in pregnancy. Int J Surg Case Rep. 2015;7C:89-92. doi:10.1016/j.ijscr.2015.01.004

43. Chang YH, Wang LJ, Chuang CK, Wong YC, Wu CT, Hsieh ML. The efficacy and outcomes of urgent superselective transcatheter arterial embolization of patients with ruptured renal angiomyolipomas [published correction appears in J Trauma. 2007 Nov;63(5):1190]. J Trauma. 2007;62(6):1487-1490. doi:10.1097/01.ta.0000221051.68550.4a

44. He W, Chen X, Ji H, Wang J, Niu Z. Emergency retroperitoneal laparoscopic partial nephrectomy for ruptured renal angiomyolipomas: a retrospective single-center series of 15 cases. BMC Surg. 2020;20(1):59. Published 2020 Mar 30. doi:10.1186/s12893-020-00723-W

45. Koo KC, Kim WT, Ham WS, Lee JS, Ju HJ, Choi YD. Trends of presentation and clinical outcome of treated renal angiomyolipoma. Yonsei Med J. 2010;51(5):728-734. doi:10.3349/ymj.2010.51.5.728

46. Seyam RM, Bissada NK, Kattan SA, et al. Changing trends in presentation, diagnosis and management of renal angiomyolipoma: comparison of sporadic and tuberous sclerosis complexassociated forms. Urology. 2008;72(5):1077-1082. doi:10.1016/j.urology.2008.07.049

47. Fazeli-Matin S, Novick AC. Nephron-sparing surgery for renal angiomyolipoma. Urology. 1998;52(4):577-583. doi:10.1016/s0090-4295(98)00236-2 
48. Yip SK, Tan PH, Cheng WS, Li MK, Foo KT. Surgical management of angiomyolipoma: nephron-sparing surgery for symptomatic tumour. Scand J Urol Nephrol. 2000;34(1):32-35. doi:10.1080/003655900750016850

49. Heidenreich A, Hegele A, Varga Z, von Knobloch R, Hofmann R. Nephron-sparing surgery for renal angiomyolipoma. Eur Urol. 2002;41(3):267-273. doi:10.1016/s0302-2838(02)00015-5

50. Boorjian SA, Frank I, Inman B, et al. The role of partial nephrectomy for the management of sporadic renal angiomyolipoma. Urology. 2007;70(6):1064-1068. doi:10.1016/j.urology.2007.07.045

51. Minervini A, Giubilei G, Masieri L, Lanzi F, Serni S, Carini M. Simple enucleation for the treatment of renal angiomyolipoma. BJU Int. 2007;99(4):887-891. doi:10.1111/j.1464410X.2006.06702.X

52. Lane BR, Aydin H, Danforth TL, et al. Clinical correlates of renal angiomyolipoma subtypes in 209 patients: classic, fat poor, tuberous sclerosis associated and epithelioid. J Urol. 2008;180(3):836-843. doi:10.1016/j.juro.2008.05.041

53. Msezane L, Chang A, Shikanov S, et al. Laparoscopic nephron-sparing surgery in the management of angiomyolipoma: a single center experience. J Endourol. 2010;24(4):583-587. doi:10.1089/end.2009.0330

54. Liu W, Qi L, Chen M, et al. Laparoscopic Retroperitoneal Enucleation-Separation Surgery for Renal Angiomyolipoma: Perioperative and Oncologic Outcomes Based on a Randomized Controlled Trial. J Endourol. 2016;30(8):901-905. doi:10.1089/end.2016.0195

55. Golan S, Johnson SC, Maurice MJ, et al. Safety and early effectiveness of robot-assisted partial nephrectomy for large angiomyolipomas. BJU Int. 2017;119(5):755-760. doi:10.1111/bju.13747

56. Qin C, Wang Y, Li P, et al. Super-Selective Artery Embolization before Laparoscopic Partial Nephrectomy in Treating Renal Angiomyolipoma. Urol Int. 2017;99(3):277-282. doi:10.1159/000472261

57. Tso WK, Wong S, Tsang J, Tung H, TaI KS, Tam PC, et al. Embolotherapy with a mixture of lipiodol and ethanol for renal angiomyolipoma J HK Coll Radiol. 2005; : 72-82

58. Ramon J, Rimon U, Garniek A, et al. Renal angiomyolipoma: long-term results following selective arterial embolization. Eur Urol. 2009;55(5):1155-1161. doi:10.1016/j.eururo.2008.04.025

59. Takebayashi S, Horikawa A, Arai M, Iso S, Noguchi K. Transarterial ethanol ablation for sporadic and non-hemorrhaging angiomyolipoma in the kidney. Eur J Radiol. 2009;72(1):139145. doi:10.1016/j.ejrad.2008.06.017

60. Chick CM, Tan BS, Cheng C, et al. Long-term follow-up of the treatment of renal angiomyolipomas after selective arterial embolization with alcohol. BJU Int. 2010;105(3):390394. doi:10.1111/j.1464-410X.2009.08813.x

61. Chan CK, Yu S, Yip S, Lee P. The efficacy, safety and durability of selective renal arterial embolization in treating symptomatic and asymptomatic renal angiomyolipoma. Urology. 2011;77(3):642-648. doi:10.1016/j.urology.2010.08.040

62. Chatziioannou A, Gargas D, Malagari K, et al. Transcatheter arterial embolization as therapy of renal angiomyolipomas: the evolution in 15 years of experience. Eur J Radiol. 2012;81(9):23082312. doi:10.1016/j.ejrad.2011.06.003 
63. Duan XH, Zhang MF, Ren JZ, et al. Urgent transcatheter arterial embolization for the treatment of ruptured renal angiomyolipoma with spontaneous hemorrhage. Acta Radiol. 2016;57(11):1360-1365. doi:10.1177/0284185115588125

64. Sheth RA, Feldman AS, Paul E, Thiele EA, Walker TG. Sporadic versus Tuberous Sclerosis Complex-Associated Angiomyolipomas: Predictors for Long-Term Outcomes following Transcatheter Embolization. J Vasc Interv Radiol. 2016;27(10):1542-1549. doi:10.1016/j.jvir.2016.05.029

65. Bardin F, Chevallier O, Bertaut A, et al. Selective arterial embolization of symptomatic and asymptomatic renal angiomyolipomas: a retrospective study of safety, outcomes and tumor size reduction. Quant Imaging Med Surg. 2017;7(1):8-23. doi:10.21037/qims.2017.01.02

66. Anis O, Rimon U, Ramon J, et al. Selective Arterial Embolization for Large or Symptomatic Renal Angiomyolipoma: 10 Years of Follow-up. Urology. 2020;135:82-87. doi:10.1016/j.urology.2019.09.035

67. Castle SM, Gorbatiy V, Ekwenna O, Young E, Leveillee RJ. Radiofrequency ablation (RFA) therapy for renal angiomyolipoma (AML): an alternative to angio-embolization and nephronsparing surgery. BJU Int. 2012;109(3):384-387. doi:10.1111/j.1464-410X.2011.10376.X

68. Han ZY, Liang P, Yu XL, Cheng ZG, Liu FY, Yu J. Ultrasound-guided percutaneous microwave ablation of sporadic renal angiomyolipoma: preliminary results. Acta Radiol. 2015;56(1):56-62. doi:10.1177/0284185113519357

69. Makki A, Graumann O, Høyer S, et al. Cryoablation of Renal Angiomyolipoma: An Evaluation of Safety and Efficacy. J Endourol. 2017;31(11):1117-1122. doi:10.1089/end.2017.0376

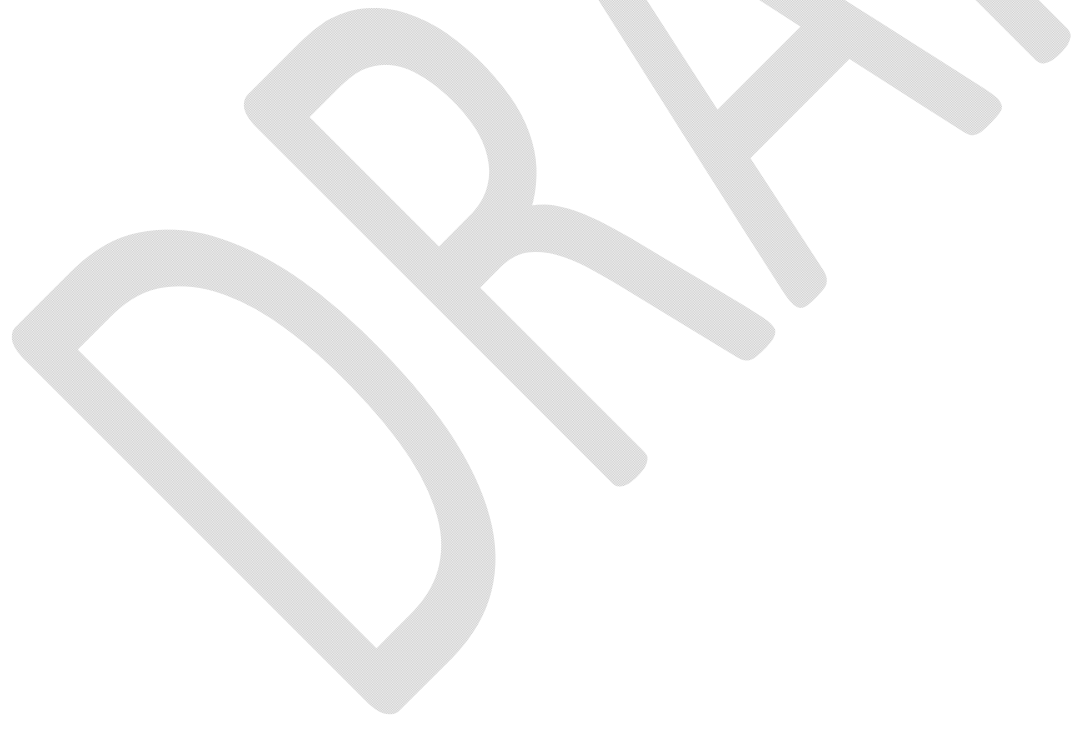




\section{Figures and Tables}

Fig. 1. PRISMA flow diagram of literature review. LAM: lymphangioleiomyomatosis; TSC: tuberous sclerosis complex.

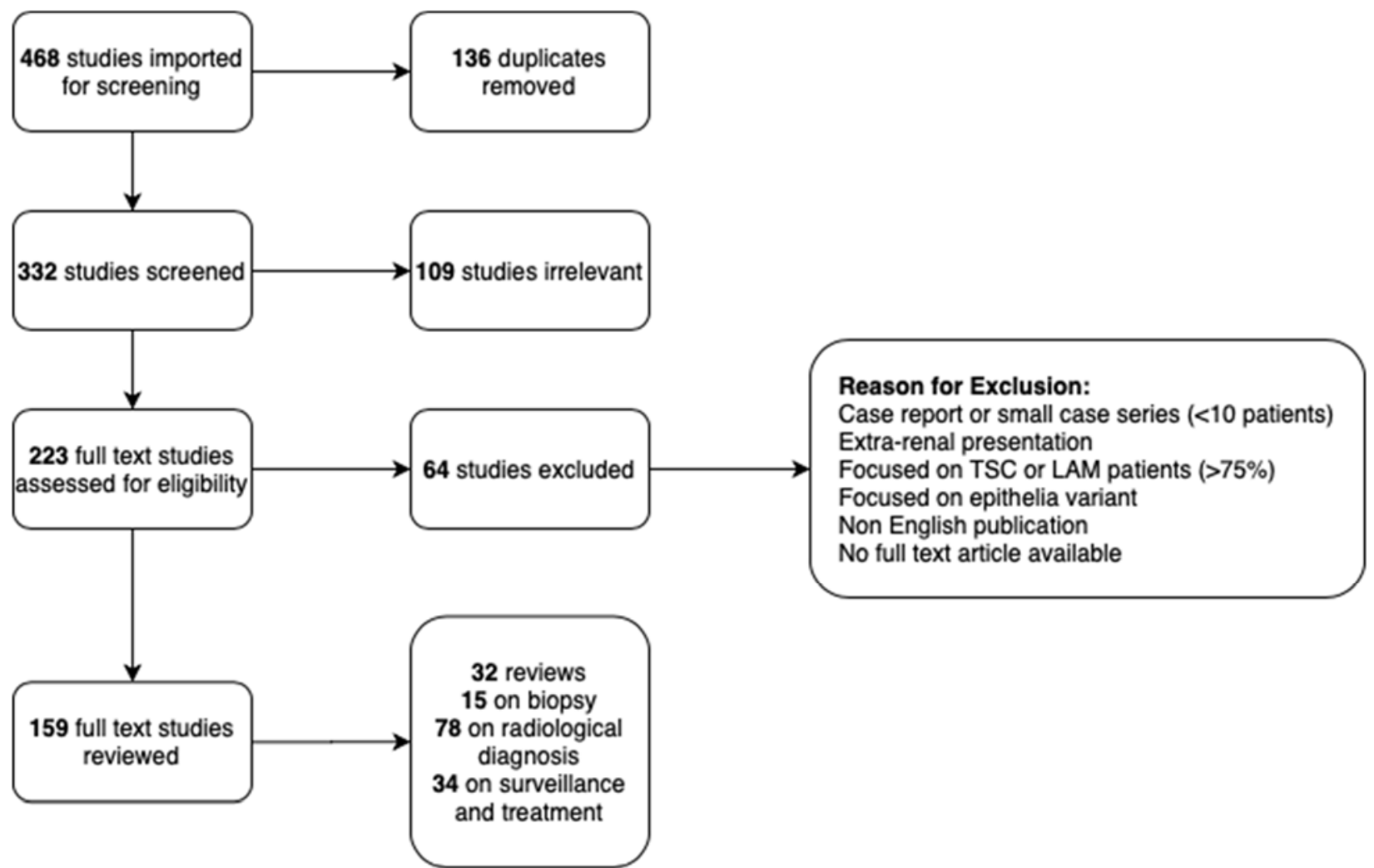


Fig. 2. Algorithm for the diagnosis and treatment of adult sporadic AMLs. ${ }^{*}$ Intervention should be considered in those that are high risk. AML: angiomyolipomas; CT: computed tomography; MRI: magnetic resonance imaging; TAE: transcatheter embolization; US: ultrasound.

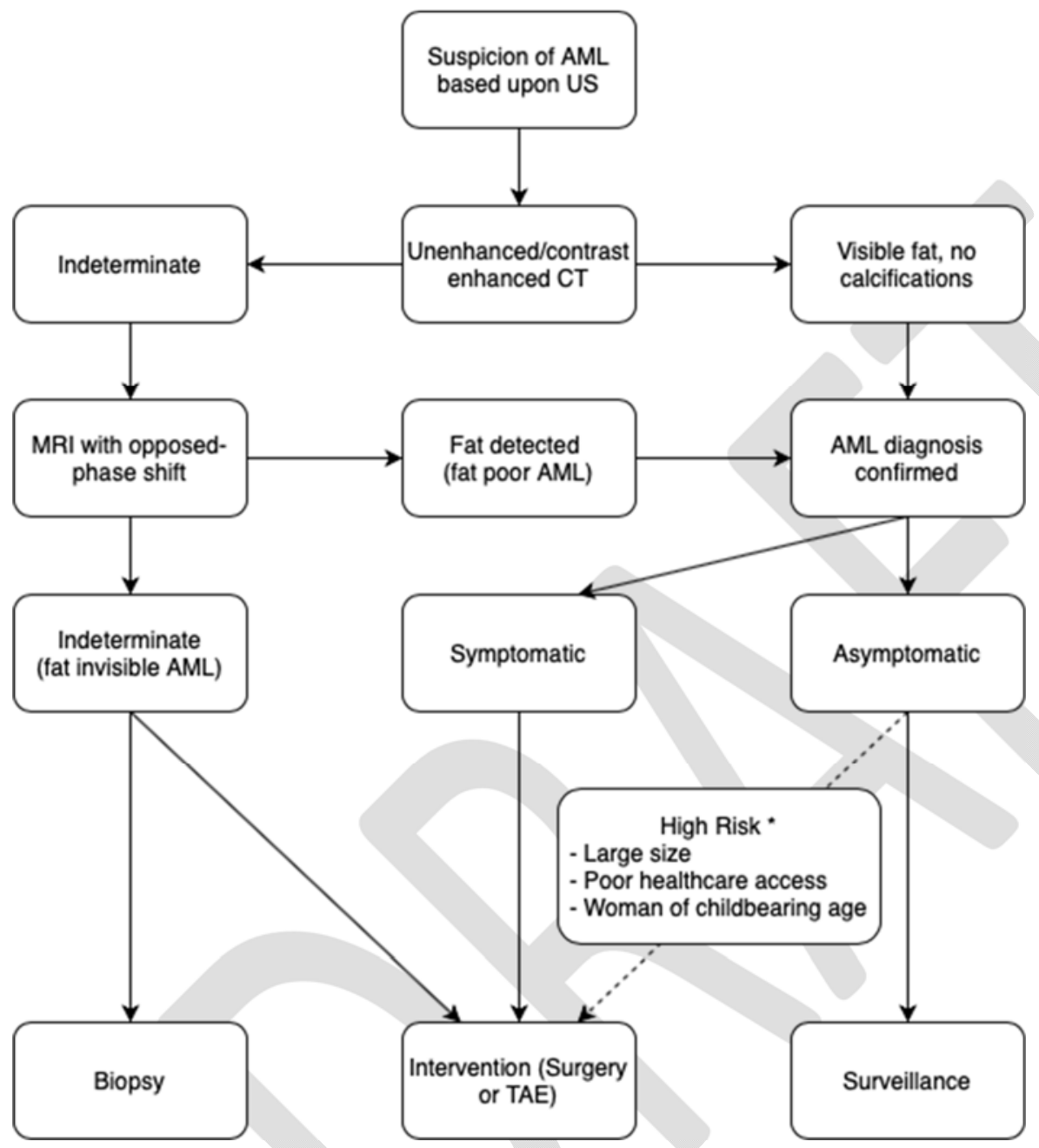




\begin{tabular}{|c|c|c|c|c|c|c|c|c|c|c|}
\hline & $=$ & 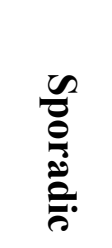 & 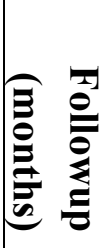 & & 를 & $\begin{array}{l}\Omega \\
0 \\
\stackrel{0}{E}\end{array}$ & 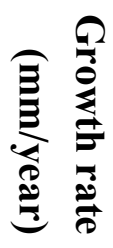 & 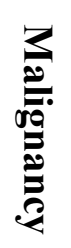 & 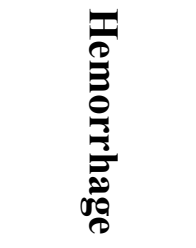 & 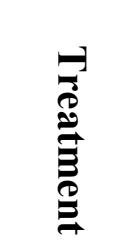 \\
\hline Sward, $2020^{32}$ & 45 & $100 \%$ & 67 & 3.4 & $87 \%$ & $47 \%$ & 2.7 & $0 \%$ & $2 \%$ & $17 \%$ \\
\hline Chan, $2018^{33}$ & 187 & $100 \%$ & 24 & 0.9 & $100 \%$ & $17 \%$ & 0.13 & & $0.5 \%$ & $3 \%$ \\
\hline $\begin{array}{l}\text { Ruud Bosch, } \\
2018^{34}\end{array}$ & 53 & $100 \%$ & 54 & & & & & $0 \%$ & $17 \%$ & $13 \%$ \\
\hline Bhatt, $2016^{5}$ & 447 & $96 \%$ & 43 & $\begin{array}{c}\text { NR } 90<4 \\
\mathrm{~cm}\end{array}$ & $90 \%$ & $9 \%$ & 0.2 & $0 \%$ & $2.5 \%$ & $6 \%$ \\
\hline $\begin{array}{l}\text { Fittschen, } \\
2014^{35}\end{array}$ & 61 & $100 \%$ & 25 & NR & $100 \%$ & $3.3 \%$ & & & & $0 \%$ \\
\hline $\begin{array}{l}\text { Maclean, } \\
2014^{29}\end{array}$ & 135 & $100 \%$ & 22 & $\begin{array}{c}\text { NR } 75 \% \\
<2 \mathrm{~cm} \\
17 \%<4 \\
\mathrm{~cm} \\
8 \%>4 \\
\mathrm{~cm}\end{array}$ & & $12 \%$ & 0.7 & & $2 \%$ & $2 \%$ \\
\hline $\begin{array}{l}\text { Ouzaid, } \\
2014^{30}\end{array}$ & 130 & $92 \%$ & 49 & $\begin{array}{l}\text { NR } 71 \% \\
<4 \mathrm{~cm}\end{array}$ & $78 \%$ & $3 \%$ & 0.9 & $0 \%$ & $3 \%$ & $13 \%$ \\
\hline Mues, $2010^{36}$ & 45 & $100 \%$ & 55 & 1.7 & 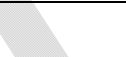 & & 0.9 & & $4 \%$ & $6 \%$ \\
\hline $\begin{array}{l}\text { De Luca, } \\
1999^{37}\end{array}$ & 33 & $97 \%$ & 60 & NR & $94 \%$ & $8 \%$ & 1 & $0 \%$ & $0 \%$ & $0 \%$ \\
\hline All & 1137 & $97 \%$ & $\begin{array}{c}37 \\
22- \\
67\end{array}$ & & $\begin{array}{c}92 \% \\
87- \\
100 \%\end{array}$ & $\begin{array}{c}9 \% \\
1- \\
47 \%\end{array}$ & $\begin{array}{c}0.4 \\
0.1- \\
1.3\end{array}$ & $0 \%$ & $\begin{array}{c}3.0 \% \\
0.5-17.0 \%\end{array}$ & $\begin{array}{c}5 \% \\
0-13 \%\end{array}$ \\
\hline$<4 \mathrm{~cm}$ & 642 & & & & $94 \%$ & $2 \%$ & $\begin{array}{c}0.6 \\
0.2- \\
0.8\end{array}$ & & $\begin{array}{c}1 \% \\
0-4 \%\end{array}$ & $\begin{array}{c}1 \% \\
0-4 \%\end{array}$ \\
\hline$>4 \mathrm{~cm}$ & 123 & & & & $68 \%$ & $25 \%$ & $\begin{array}{c}0.6 \\
0.2- \\
0.9\end{array}$ & & $\begin{array}{c}16 \% \\
6-31 \%\end{array}$ & $\begin{array}{c}34 \% \\
23- \\
38 \%\end{array}$ \\
\hline
\end{tabular}




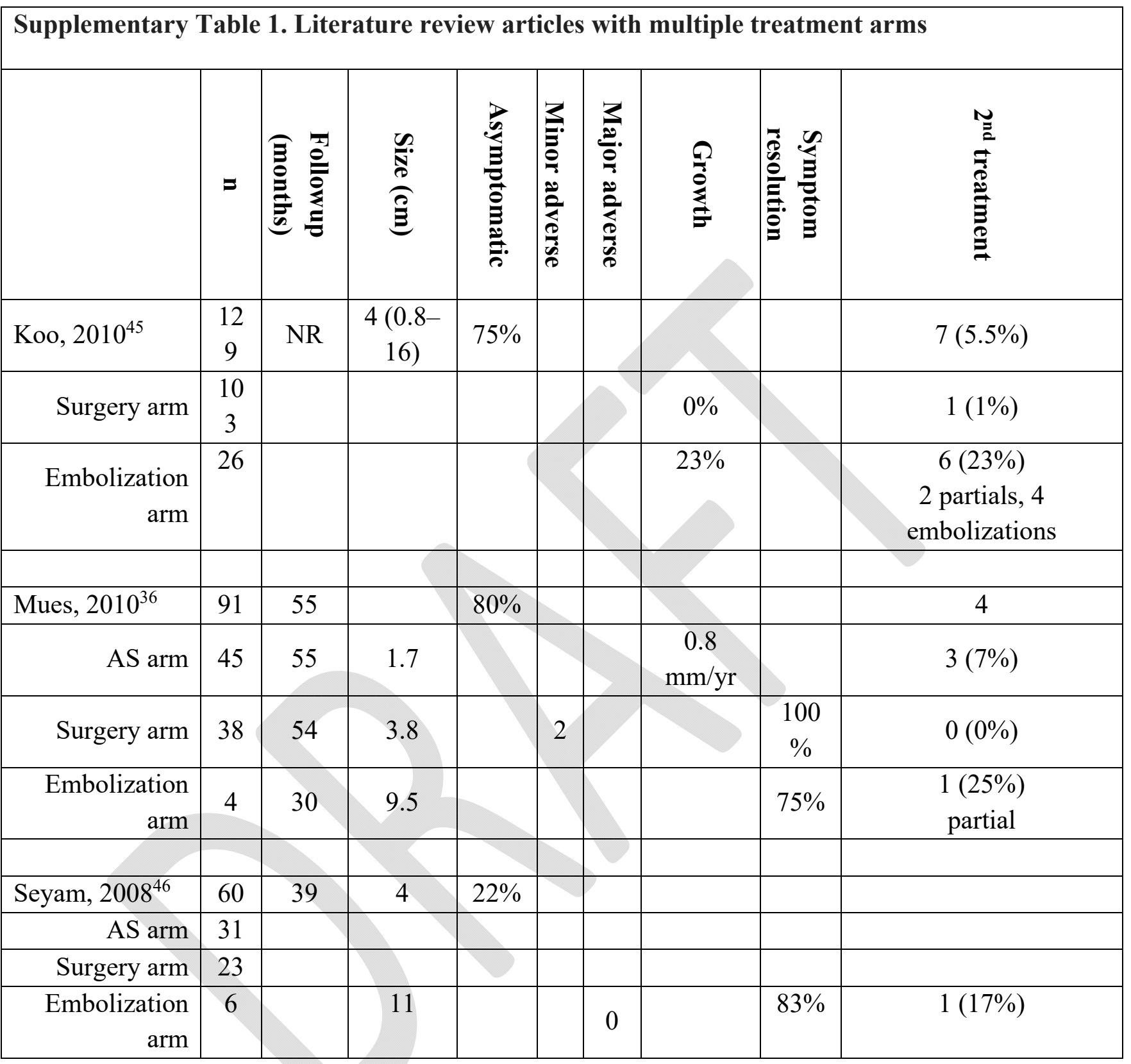

It must be noted that these were all retrospective and did not have evidence of randomization. 


\begin{tabular}{|c|c|c|c|c|c|c|c|c|c|c|c|}
\hline & $=$ & 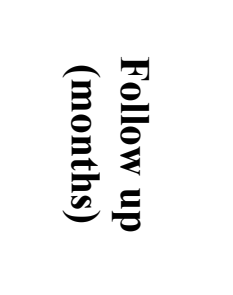 & 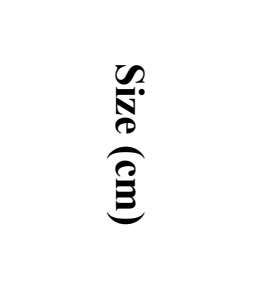 & 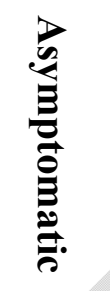 & 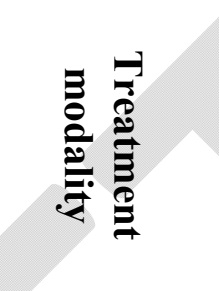 & 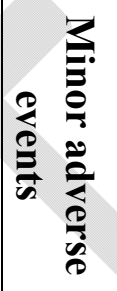 & 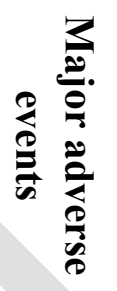 & $\begin{array}{l}\frac{\Omega}{0} \\
\stackrel{z}{E}\end{array}$ & 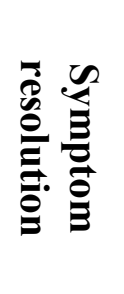 & 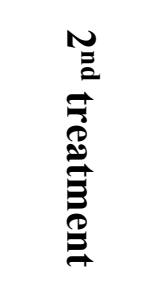 & 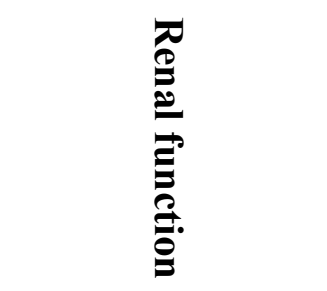 \\
\hline Fazeli-Matin, $1998^{47}$ & 27 & 39 & $7(1.5-26)$ & $48 \%$ & $\begin{array}{l}\text { Partial and } \\
\text { radical }\end{array}$ & 6 & 1 & $0 \%$ & $100 \%$ & 0 & $\begin{array}{c}\text { Preop Cr } 1.05, \\
\text { postop } 1.43\end{array}$ \\
\hline Yip, $2000^{48}$ & 23 & $26(1-80)$ & $12.3(1.5-30)$ & $30 \%$ & $\begin{array}{c}\text { Partial and } \\
\text { radical }\end{array}$ & 1 & 1 & $4 \%$ & $100 \%$ & $1(\mathrm{RN})$ & NR \\
\hline De Luca, $1999^{37}$ & 20 & NR & $8.1(2.5-17)$ & $55 \%$ & $\begin{array}{l}\text { Partial and } \\
\text { radical }\end{array}$ & NR & NR & NR & NR & NR & NR \\
\hline Heidenreich, $2002^{49}$ & 28 & $58(3-114)$ & $5.5(2.5-15)$ & & $\begin{array}{c}\text { Not } \\
\text { specified }\end{array}$ & 3 & 3 & $0 \%$ & $100 \%$ & 0 & $\begin{array}{c}\text { Preop Cr 0.9, } \\
\text { postop } 1.2\end{array}$ \\
\hline Boorjian, $2007^{50}$ & 58 & $96(9-89)$ & $3.9(0.8-12.5)$ & $41 \%$ & Partial & 19 & 4 & $4 \%$ & $100 \%$ & $\begin{array}{c}1 \\
\text { (emboli } \\
\text { zation) }\end{array}$ & $\begin{array}{c}\text { Preop } \mathrm{Cr} 1 \text {, postop } \\
1.1\end{array}$ \\
\hline Minervini, $2007^{51}$ & 37 & $56(10-120)$ & $5.2(1.5-15)$ & $49 \%$ & Partial & 4 & 1 & $0 \%$ & & 0 & $\begin{array}{c}\text { Preop Cr } 0.95, \\
\text { postop } 0.99\end{array}$ \\
\hline Lane, $2008^{52}$ & $\begin{array}{c}20 \\
9\end{array}$ & $41(0-288)$ & 4 & $50 \%$ & $\begin{array}{c}\text { Not } \\
\text { specified }\end{array}$ & & & $0 \%$ & NR & 0 & NR \\
\hline Msezane, $2010^{53}$ & 14 & 29 & 2 & & Partial & 1 & 1 & $0 \%$ & & $\begin{array}{c}1 \text { (SAE } \\
\text { after } \\
\text { hemorrh } \\
\text { age and } \\
\text { NSS) }\end{array}$ & $\begin{array}{c}\text { Preop GFR 99, } \\
\text { postop } 84\end{array}$ \\
\hline
\end{tabular}




\begin{tabular}{|c|c|c|c|c|c|c|c|c|c|c|c|}
\hline Lin, $2018^{20}$ & 23 & $40(31-62)$ & 5.2 & & Partial & 5 & 0 & $0 \%$ & & 0 & $\begin{array}{l}\text { Preop GFR } 102, \\
\text { postop } 100\end{array}$ \\
\hline Liu, $2016^{54}$ & 40 & 23 & 6.2 & & Partial & 2 & 1 & $0 \%$ & & 0 & $\begin{array}{c}\text { Preop GFR 43, } \\
\text { postop } 34\end{array}$ \\
\hline Golan, $2017^{55}$ & 40 & $8(1-15)$ & $7.2(5-8.5)$ & $75 \%$ & Partial & 7 & 1 & $2.50 \%$ & 100 & $\begin{array}{c}1 \\
\text { (emboli } \\
\text { zation }\end{array}$ & $\begin{array}{c}\text { Preop Cr } 0.85, \\
\text { postop NR }\end{array}$ \\
\hline Qin, 2017 56 & 36 & & 8.5 & & $\begin{array}{c}\text { Partial } \pm \\
\text { embolizatio } \\
n\end{array}$ & 4 & 0 & $0 \%$ & $100 \%$ & 0 & $\begin{array}{c}\text { NSS }<33 \% \text { GFR, } \\
\text { NSS } / \text { SAE }<15 \% \\
\text { GFR }\end{array}$ \\
\hline
\end{tabular}

AML: angiomyolipomas; Cr: creatinine; GFR: glomerular filtration rate; NSS: nephron-sparing surgery; SAE: selective arterial embolization. 


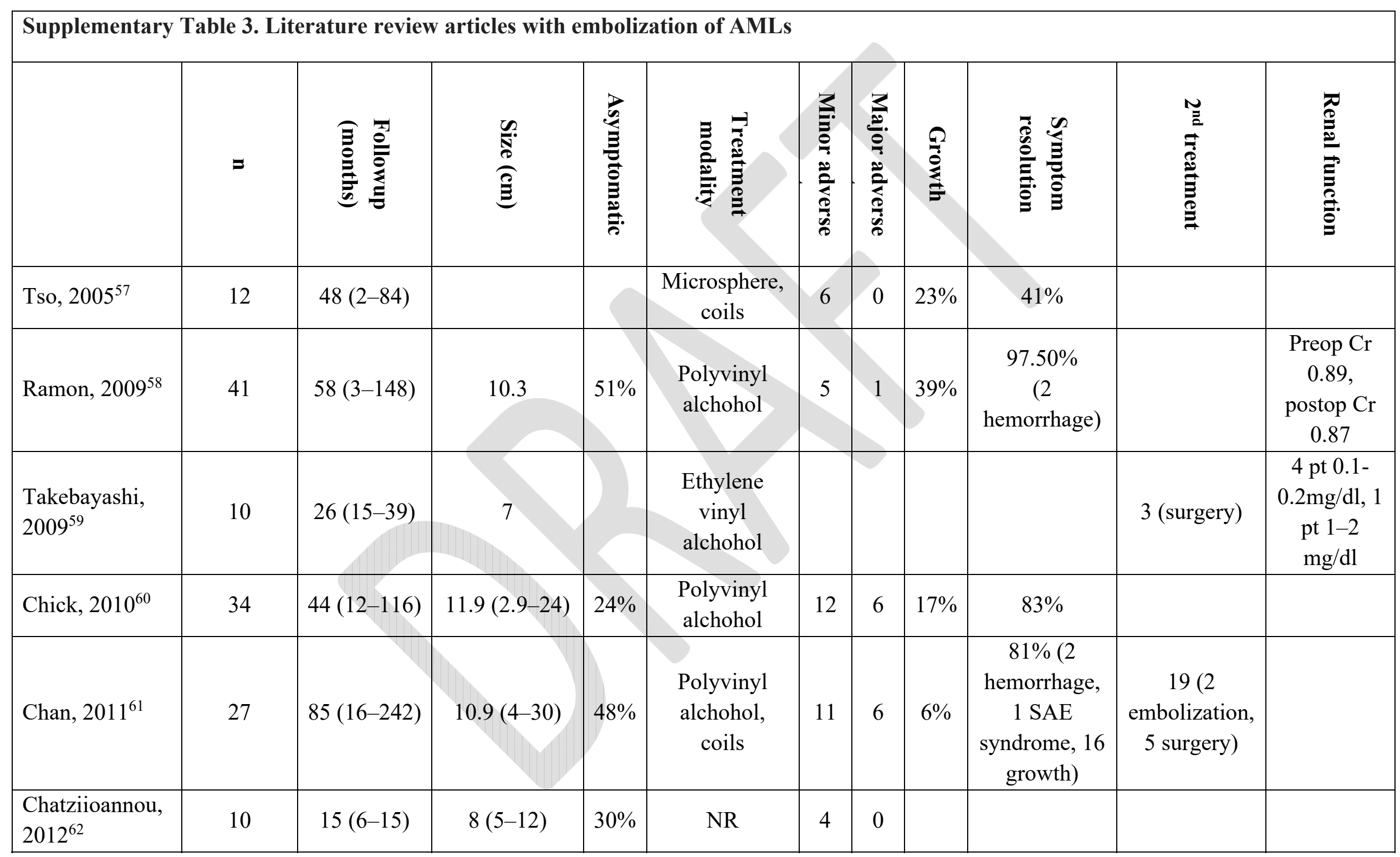




\begin{tabular}{|c|c|c|c|c|c|c|c|c|c|c|c|}
\hline Duan, $2016^{63}$ & 25 & $50(24-72)$ & $12.7(7.8-14)$ & $0 \%$ & $\begin{array}{l}\text { Polyvinyl } \\
\text { alchohol, } \\
\text { coils }\end{array}$ & 15 & 2 & $4 \%$ & $96 \%$ & & $\begin{array}{c}\text { Preop GFR } \\
59 \text { postop } \\
\text { GFR } 74\end{array}$ \\
\hline Sheth, $2016^{64}$ & 17 & $54(2-266)$ & $6.7(3.3-14.6)$ & $76 \%$ & $\begin{array}{c}\text { Microspheres, } \\
\text { coils, gelatin, } \\
\text { alcohol }\end{array}$ & 6 & 2 & & & $\begin{array}{c}2 \\
\text { (embolization }\end{array}$ & \\
\hline Bardin, $2017^{65}$ & 23 & $21(0-56)$ & 8.9 & $74 \%$ & $\begin{array}{c}10 \text { different } \\
\text { agents }\end{array}$ & 15 & 7 & $13 \%$ & $\begin{array}{c}91 \% \text { (7 } \\
\text { hemorrhage, } \\
2 \text { symptoms, } \\
4 \text { growth) }\end{array}$ & $\begin{array}{c}13 \text { ( } 8 \\
\text { embolization, } \\
5 \text { surgery) }\end{array}$ & $\begin{array}{c}\text { Preop GFR } \\
78 \text { postop } \\
\text { GFR } 77\end{array}$ \\
\hline Anis, $2020^{66}$ & 68 & 121 & 9.8 & $46 \%$ & $\begin{array}{c}\text { Ethanol and } \\
\text { polyvinyl } \\
\text { alcohol }\end{array}$ & NR & 2 & & $80 \%$ & $\begin{array}{c}32(4 \\
\text { surgery, } 28 \\
\text { embolization) }\end{array}$ & $\begin{array}{c}\text { Postop } \\
\text { GFR } 82\end{array}$ \\
\hline
\end{tabular}

AML: angiomyolipomas; Cr: creatinine; GFR: glomerular filtration rate; NSS: nephron-sparing surgery; SAE: selective arterial embolization. 


\begin{tabular}{|c|c|c|c|c|c|c|c|c|c|c|c|c|}
\hline \multicolumn{13}{|c|}{ Supplementary Table 4. Literature review articles with ablation of AMLs } \\
\hline & $\mathbf{z}$ & 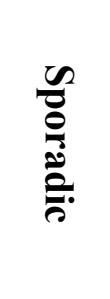 & 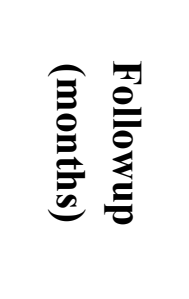 & 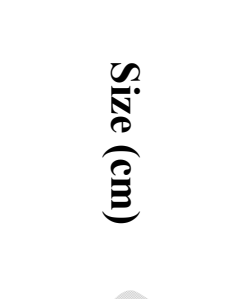 & 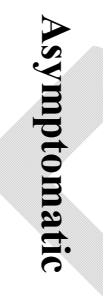 & 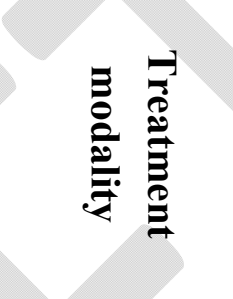 & 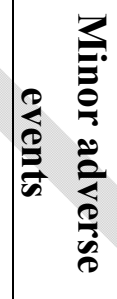 & 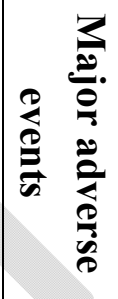 & $\begin{array}{l}\Omega \\
\stackrel{2}{0} \\
=\end{array}$ & 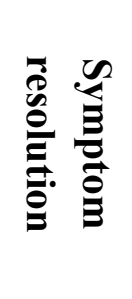 & 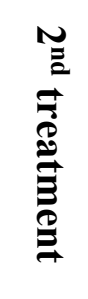 & 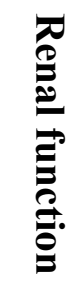 \\
\hline Castle, $2012^{67}$ & 15 & $100 \%$ & $21(1-72)$ & $2.6(1-3.7)$ & & $\begin{array}{c}\text { RFA (5 lap, } \\
10 \text { perc) }\end{array}$ & 3 & NR & & & NR & NR \\
\hline Han, $2015^{68}$ & 14 & $100 \%$ & $10(6-36)$ & $3.4(0.8-6.1)$ & $36 \%$ & Microwave & 12 & 1 & $0 \%$ & $100 \%$ & 0 & NR \\
\hline Makki, $2017^{69}$ & 16 & $75 \%$ & $25(12-33$ & 4.7 & & Cryotherapy & & & & & NR & NR \\
\hline
\end{tabular}

AML: angiomyolipomas. 